\title{
16. What could transport planning practice learn from public participation GIS method?
}

\author{
Miloš N. Mladenović, Marketta Kyttä, Kirsi \\ Forss and Maarit Kahila-Tani
}

\subsection{INTRODUCTION}

Steps away from the 'predict and provide' transport planning paradigm have been recognized since the 1970s (Hensher, 1979) and increasingly in the last two decades (Bertolini et al., 2008). This ongoing paradigm change should lead to human scale transport planning where mobility solutions are planned from the perspective of people and are based on improved understanding of the lifestyles, mobility choices and experiences of individuals (Weckström et al., 2019; Glavić et al., 2019). Today, transport planning practice is gradually recognizing the limitations of the solely quantitative approach, emphasizing the political dimension in the process of breaking out of car dependency (Banister, 2008; Kennedy et al., 2005; Sustar et al., 2020). Contrastingly, in planning theory, public engagement has been seen as an important aspect of planning processes, benefiting not only the procedural or outcome justice, but also improving the quality of decisions and enabling transformative process development (Healey, 1992; Innes, 2004; Ward, 2001; Willson, 2001).

Despite efforts in practice and theory, mainstreaming public engagement also remains one of the crucial factors for the evolution of transport-planning practice. This is evident in the development of Sustainable Urban Mobility Plans (SUMP), the common European Union urban transport planning framework (May, 2015), where citizen and stakeholder involvement is essential. In addition to this exemplary institutionalization of participatory transport planning within SUMP, the topic has attracted researchers' attention, for example to understand value conflicts (Barnes and Langworthy, 2004), assess inclusivity of participatory processes (Booth and Richardson, 2001), choose target participants (Comeau and Rodriguez, 2000), measure participation 
performance (Bailey et al., 2015) and recommend cost-effective strategies and procedural improvements (Casello et al., 2015; Lee et al., 2017).

Despite the range of efforts aimed at advancing participatory planning practices, the need for further development of public engagement methods and participatory planning practices remains (Bickerstaff et al., 2002). The palette of traditional methods, such as public meetings, exhibitions and focus group sessions (Ibeas et al., 2011), has been extended during the last two decades with a variety of digital and web-based tools (Luna-Reyes et al., 2012). These tools have been developed as a response to several challenges in the dominant planning practice: face-to-face participation can only involve a handful of activists; participation often focuses solely on resisting changes; public engagement is typically initiated too late into the planning process and the collected data might remain invisible (Kahila-Tani et al., 2019). Responding to these challenges, agencies nowadays have at their disposal a range of digital tools, including for example online discussion portals (Lowry, 2010), visualization tools (Cheu et al., 2011), social media (Evans-Cowley and Griffin, 2012) and crowdsourcing applications (Misra et al., 2014).

Public participation geographic information system (PPGIS) methods are among the most widespread web-based methods. PPGIS methods have a rich and diverse conceptual history that draws upon several intellectual traditions including critical theory, community development, liberal democracy and social justice theory, anthropology and ethnography, political ecology and philosophies of science (Kahila-Tani, 2015). PPGIS methodology enables residents to communicate localized experiential knowledge about their place-based experiences, behaviour patterns or suggestions for planning alternatives. This georeferenced input can be in the form of point, line or area map-based markings, allowing large datasets to be collected (Figure 16.1). Thus, an advantage of using georeferenced data is the possibility for direct conversion into standard GIS formats (Brown, 2012; Brown and Kyttä, 2014), and an opportunity to link user knowledge to existing infrastructure or proposed planning solutions. Moreover, PPGIS methods enable an objective assessment of the distribution, type and/or intensity of values that individuals deliver (Brown and Raymond, 2014). In Finland, PPGIS methodology has been developed in a close cooperation with planners, thus allowing the methodology to have a direct relevance for planning and decision-making processes (Kahila-Tani et al., 2016).

So far, despite some isolated efforts (Prevost, 2006; Schlossberg and Brehm, 2009; Tang and Waters, 2005; Zhong et al., 2008), the development and implementation of PPGIS tools has been mostly on the fringes of the transport planning field (Ganapati, 2010). In addition, previous reviews of PPGIS methods have focused on the use of PPGIS in research (Brown and Kyttä, 2014), in urban planning practice (Kahila-Tani et al., 2019) and in natural resource management (Brown et al., 2020). However, a review that can provide lessons for 

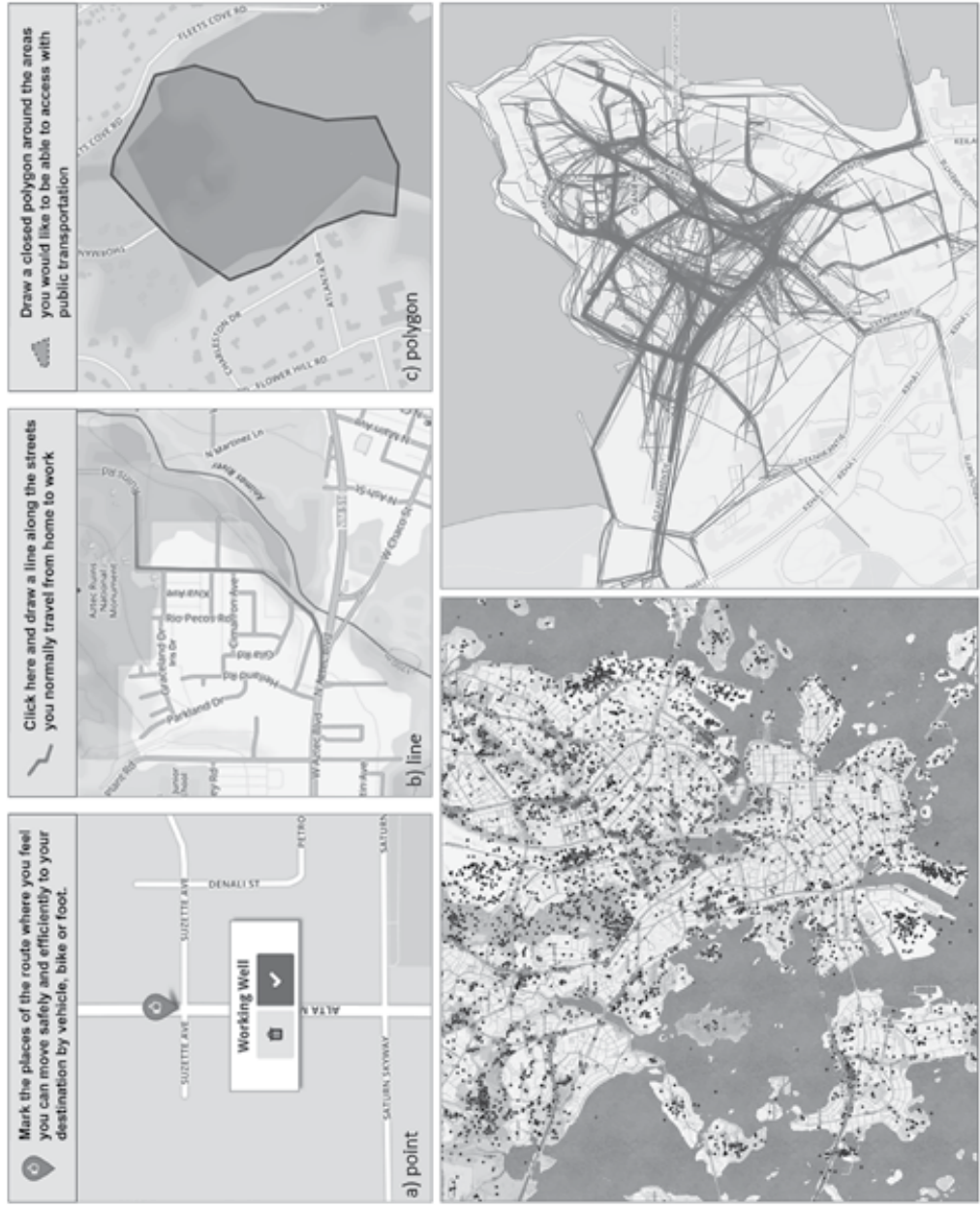

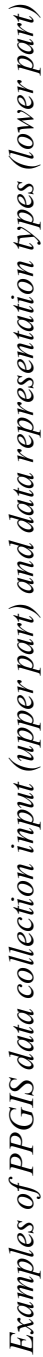

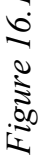


transport planning practice is missing. This research aims to fill this gap. This chapter reviews actual PPGIS experiences in transport planning processes from the United States (US), the United Kingdom (UK), Finland, the Netherlands, Australia and New Zealand. An analysis of PPGIS questionnaires used in 47 participatory transport planning projects, together with questionnaires of experts utilizing the questionnaire tool, reveals some essential pros and cons of PPGIS methodology in transport planning. In particular, we discuss whether the PPGIS methodology promotes effective arrangements of public participation, helps to reach a broad spectrum of participants, or produces high-quality and versatile knowledge.

\subsection{METHODOLOGY}

Previous reviews of PPGIS methods inform us that purpose, geographic context, data quality, sampling approaches, data collection, data ownership and dominant mapping technology vary depending on the project (Brown and Kyttä, 2014; Kahila-Tani et al., 2019). The methodology used in this review consists of two complementing parts. The first part is an ex post evaluation of 47 transport projects that have implemented the Maptionnaire PPGIS method for public engagement. Maptionnaire is an advanced example of PPGIS methodology developed originally at Aalto University, and the authors had access to the data of projects realized using this tool.

To start the review process, over 400 planning projects using Maptionnaire for public engagement were identified through forward and backward snowballing. The search focused on the period between November 2013 and May 2017, and was stopped when a saturation point was reached, that is, when no new projects could be identified. From this set of projects, those that focused on transport planning were selected, resulting in 47 projects, which were implemented in Finland ( 49 per cent), the UK ( 21 per cent), the US ( 15 per cent), New Zealand ( 9 per cent), Australia (4 per cent) and the Netherlands ( 2 per cent). The review of projects includes analysis of transport modes in the project's scope, project type, area scale, structure of questionnaire used, and number of respondents, data and points collected.

The second part of the study included an ex post expert questionnaire, aimed at reviewing additional experiential lessons from the persons responsible for organizing the questionnaire, which cannot be drawn from project evaluation itself. This questionnaire was sent to the identified individuals responsible for public participation in the organizations leading the aforementioned 47 projects (total 32 organizations), and was open during June 2017. The questionnaire included questions related to organization type, experts' position in the organization and their educational background. The questionnaire used mostly open questions about the following topics: Why did you want to have online 
participation in your project? What were the surprising results from your data collection, if applicable? What were the benefits for the project from using online participation? What were the challenges in using online participation in your project? Would you recommend this tool to a fellow transport planner?

\subsection{ANALYSIS OF IMPLEMENTED PPGIS PROJECTS}

\subsubsection{Overview of Implemented Projects}

The project types where PPGIS questionnaires were used varied from the development of strategic transport visions of whole cities to providing comments about detailed road designs. Most of the projects ( 55 per cent) focused on improvement of transport services, such as connectivity of bus lines. In addition to that, PPGIS questionnaires were used to collect background information for development of transport strategies and visions of cities (21 per cent), with a purpose to create guidelines; for example, on how to support walkability and cycling by urban design, or how to improve safety of the cyclists. Fifteen per cent of the projects related to land use planning, where opinions were asked related to road projects. Topics classified as 'other' ( 9 per cent) were related to, for example, mapping the interests of specific stakeholders (for example, companies) regarding road building projects. Regarding the transport modes of the 47 reviewed projects, the most frequent type ( 47 per cent) was multimodal transport. The focus of many questionnaires was on pedestrians and cycling (19 per cent), or public transport planning (17 per cent), while questionnaires were rarely created about plans solely for vehicular traffic ( 9 per cent) or rail (4 per cent). The group 'other' ( 4 per cent) includes questionnaires that did not deal with any mode in particular, but rather focus on a certain objective, such as traffic safety. Regarding the geographic scope of the questionnaires, most of the projects were city-wide (66 per cent). The second group of projects related to a larger scale (19 per cent), such as intercity or state-wide projects, while the smallest number of projects focused on a smaller scale, such as neighbourhood ( 9 per cent), city centre ( 4 per cent) or detailed design ( 2 per cent).

\subsubsection{Questionnaire Structure in Implemented Projects}

The analysis of questionnaire structure shows that the length of the questionnaire varied between two and 20 pages, with median being seven, and the most frequent number of pages was 14 . This kind of high variation is possible because the transport experts designed the questionnaires themselves and thus the quality and content of the questionnaires varied a lot. The questionnaires were implemented using a range of traditional question types, such as radio 
buttons, open answers and dropdown lists. These question types were used to gather background information about the respondents as well as about the project, or for rating the project ideas or the connections.

An essential element of map questionnaires is options for map-based answers, in the form of point, line or polygon. Point markers were used in almost all questionnaires (44), line strings in 23 and polygons in one questionnaire. In total, 226 point questions, 54 line strings and 3 polygon questions were used in the questionnaires (Table 16.1). Points were used to mark positive and negative issues on the map, strings for routes, while polygons were used to define areas that need improvement or development. Average and median for each map answer types per questionnaire were five for points, and one for both line and polygon questions. The questionnaire developers had also used additional geographic datasets, most often in geoJSON or shapefile formats, sometimes raster overlays, to mark additional map features - for example, planned infrastructure - to provide additional contextual information for respondents.

\subsubsection{Respondents and Data Points in Implemented Projects}

The analysis of respondents and data points of map questions from the 47 projects shows that there were 50904 respondents, who marked 80052 map data points in total. A questionnaire had an average of 1126 respondents. The summation of the number of respondents, data points, and their ratio are classified by transport modes and project types in Table 16.1. The ratio between the number of respondents and the number of data points collected reveals that there are projects that have a small ratio value (for example, 0.31 ), meaning that a high number of respondents have not provided answers to the map-related questions. On the contrary, there are projects, such as those on public or multimodal transport that have around two data points per respondent (1.91 and 1.94, respectively). Further analysis revealed that the relationship between the number of pages and the number of respondents/data points was not linear, and there are other factors contributing to the amount of collected data than the length of the questionnaire.

\subsection{EXPERT QUESTIONNAIRE ANALYSIS}

Out of the 34 experts who received the questionnaire, 21 responded (61.8 per cent). With regard to organization type, six respondents were from transport planning, six from consultancy, five from city planning, and six from other types of organizations such as governmental organizations. Most of the respondents identified themselves as city planners, and only a few as transport planners or project managers. Nevertheless, most respondents had their background in transport engineering and only a few in planning geography, 


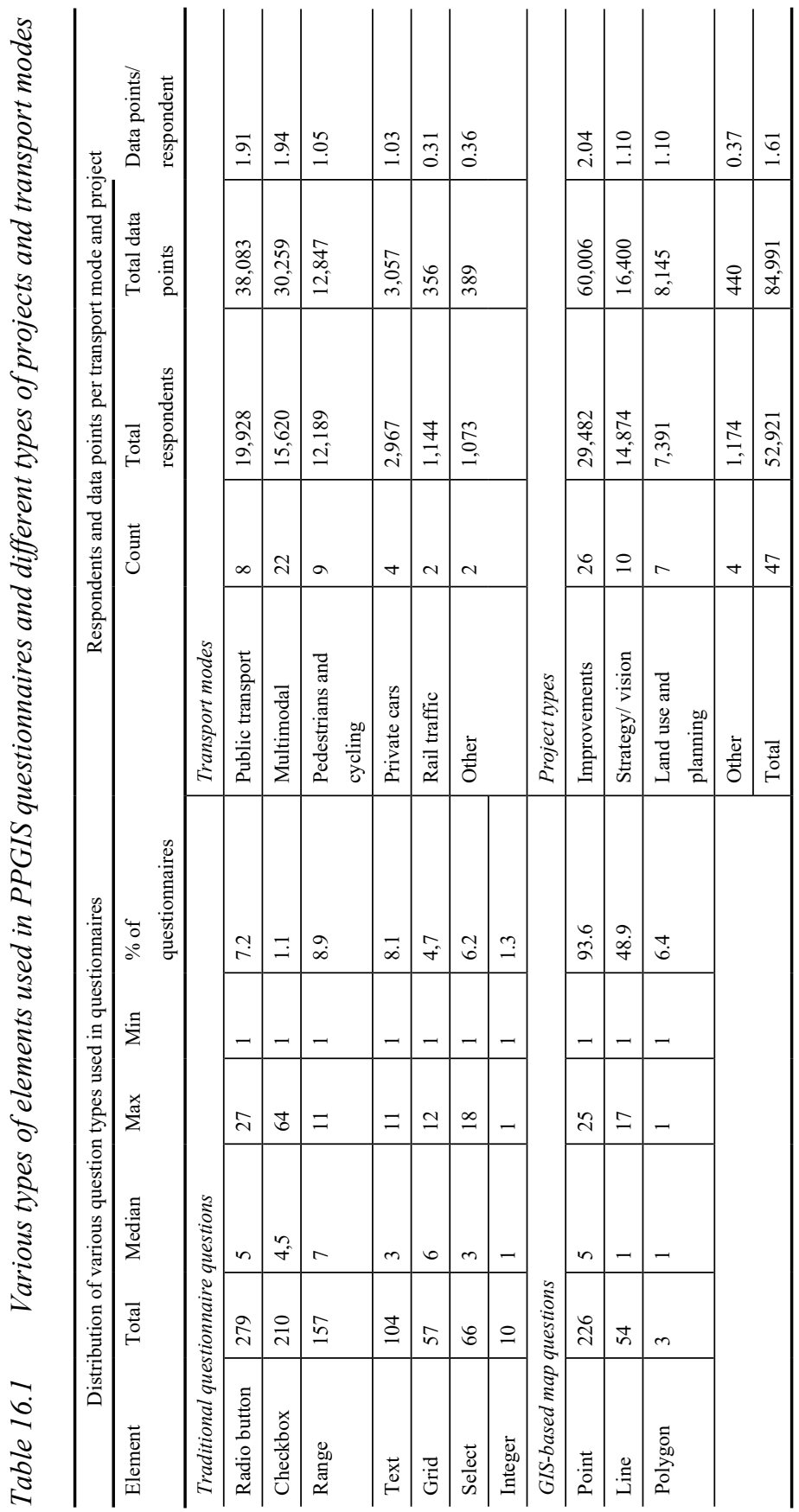


architecture or spatial planning. The respondents were asked whether they would recommend the tool to a fellow planner, with a ranking from 1 to 10 (maximum). The responses varied between 8 and 10, with the mean being 9.33, and the median 10. Consequently, respondents would highly likely recommend PPGIS method to another expert, although there might be positive bias from those answering the survey.

\subsubsection{Benefits of PPGIS}

Experts stated a range of reasons for using online methods in public engagement. For some, community engagement is an essential element of the current organizational practice, and many stated that their agency had extensively used web tools before to complement face-to-face engagement. The possibility to achieve a high total number of respondents and high diversity of participants was among the main benefits of the PPGIS method. Several experts highlighted the ease of using the tool: for residents to answer online questionnaires and to provide input as opposed to other methods; for demonstrating plans and other visual features on a questionnaire map; for utilizing data that is already collected in a digital format; for marketing a web-based questionnaire using social media or other means; for importing georeferenced data into GIS analysis software; and for developing questionnaires by using ready-made PPGIS tools together with different organizations within the municipality.

Further benefits identified included the possibility to collect opinions beyond standard questionnaire answers, including individual experiential understanding, wishes, unexpected positive/negative effects or more straightforward plan recommendations. Experts also valued the possibility to collect feedback in a geographic context, taking into account other spatial information such as the built environment, as well as a possibility to collect input about multiple locations or a wide area. In addition, the flexibility of implementation in different project stages was highlighted because this helps in refining the planning process itself, and allows a follow-up study in a particular neighbourhood. Several experts stated that the number of map answers and their statistical significance, the number and depth of open answers related to everyday experiences, and the differences in answers based on location, surprised them after completing the data collection and analysis processes. Some experts also expressed their surprise with the conflicting aspects in the citizens' answers. PPGIS datasets often provided support for the agency's analyses and interpretations and helped in validating and defending planning decisions. Experts also highlighted the benefit of reaching different target groups using questionnaire customization. Finally, online participation was sometimes seen to increase public interest in ongoing plans and development thanks to the good user 
experience with PPGIS tool. For some experts this meant utilizing the PPGIS questionnaire as a way to increase the reputation of the municipality.

\subsubsection{Challenges of PPGIS}

In addition to benefits from using PPGIS methodology, experts also identified some challenges. While some experts valued a high amount of data, others found challenges in analysing large datasets. Especially, the analysis of large numbers of open comments from citizens has been deemed to be difficult and time-consuming. Several experts identified the challenges participants face when using the questionnaire tool, especially questionnaires with many georeferenced questions and map-based questions that require input in the form of route or area. Besides the above-mentioned challenges that are especially related to the PPGIS tool, there is a set of challenges that can be considered generalizable for all web-based questionnaires. Here experts mentioned that lengthy questionnaires or answering options might lead to respondents dropping out. As in the general case of stated-preference questionnaires, experts highlighted the limits to what respondents can suggest based on the descriptions of hypothetical situations in the built environment. Another general challenge emphasized is that respondents' input is highly dependent on the way questions and information are formulated and presented online. Many experts expressed concerns that the use of digital tools might exclude some potential respondents. The anonymity of respondents may make it impossible to know whether the answers are from the same respondent, especially in longitudinal studies. Some experts were afraid of the preparation effort and the need to coordinate the agency's communication and marketing processes to attract respondents. These lead to challenges in estimating total costs, but also in learning how to implement new methodology, which is in turn related to actors involved and previous knowledge in the agency.

\subsection{DISCUSSION AND CONCLUSION}

This research aimed to provide an overview of efforts using the online public participation GIS method for public engagement in transport planning. The review of 47 implementation cases and expert questionnaire provided an insight into arguments pro and contra this public engagement method. This section provides reflections on lessons for participatory transport planning processes, with recommendations on implementing digital public engagement tools and developing participation planning practices.

According to the study, the advantages and challenges of the use of PPGIS methods in transport planning are very similar to those identified in participatory planning projects in urban and regional planning more widely. The pros 
and cons represent three perspectives that Kahila-Tani et al. (2019) identified as essential in participatory urban planning cases: (1) ability to reach a broad spectrum of people; (2) effective arrangements of public participation; and (3) the production of high-quality and versatile knowledge.

According to the experts surveyed in this study, among the main advantages of the PPGIS method is the capability to collect large data volumes with little effort and to facilitate the inclusiveness of wider and new groups. The average number of respondents of a PPGIS questionnaire in the studied transport planning projects was over 1100 participants. Although the number could be still higher, it is clearly more than take part in a typical traditional public hearing or focus group meeting. The PPGIS method is quite flexible to accommodate different requests for public engagement, thus being highly transferable. This was evidenced by a wide variety of elements used in the questionnaires. When using PPGIS questionnaires, conflicting views can also be identified, to the surprise of the experts. An advantage identified in the PPGIS literature (Brown, 2015) is that the method provides an opportunity for individual input, allowing the opinion diversity to emerge, as people can share their personal, experiential, georeferenced knowledge, while not being affected by direct interaction with other people. In addition, the experts were concerned about the digital divide, as online methods can exclude some participants. This is related to one of the greatest challenges of the PPGIS method, namely the danger of skewed geographical and socio-economical representativeness. According to Kahila-Tani et al. (2019), it seems that the data collection strategy matters. Large datasets and personal invitations that are based on random sampling seem to promote good representativeness in PPGIS questionnaires, while open marketing of questionnaires typically creates problems in reaching a balanced respondent profile.

The experts found the PPGIS method easy to implement, and the method supports data collection at various geographical scales, various phases of the planning process and in projects related to different transport modes. PPGIS method implementation is highly dependent on the effectiveness of an agency's planning processes, and coordination with other processes such as marketing. Thus, challenges of integrating PPGIS data into an agency's practice and decision-making processes can be significant, and can consequently involve much time and cost, even if the participatory method itself is intended to be cost-efficient. The experts saw that the PPGIS method is well suited for enhancing the agency's and city's reputation, as well as for supporting the development of participatory culture in both the agency and civil society. Despite its advantages, technology is not the sole answer to issues of participatory planning. The PPGIS method should be integrated with other public engagement activities, especially face-to-face activities, because wider inclusion of both collective and individual participation methods is needed to 
reach a broader spectrum of people, embracing a plurality of societal voices (Staffans et al., 2020). Nonetheless, the focus on implementation should be in the early phases of planning process, allowing for the benefits from data volume and method flexibility to improve both the decisions and the process itself.

From an agency's perspective, the PPGIS method has also the advantage of providing new types of knowledge that are usable in decision-making. The data format supports data sharing and collaboration with various sectors, and it allows easy integration into existing systems, especially into GIS and statistical analysis platforms. On the other hand, based on the type of data, there is room for expert misuse, for example through cherry picking to support existing presumptions. Moreover, some agencies may not have competent analysis or visualization skills to analyse large quantities of data. Despite the highlighted ease of creating PPGIS questionnaires, an agency with little previous experience in creating web-based questionnaires should dedicate special attention to understanding the necessary requirements for a successful questionnaire design and outreach. Agency challenges with big and qualitative data can be partially answered though opening data, organizing hackathons, as well as encouraging collaboration on co-analysis with citizen advocacy groups. Accounting for citizens as central actors in participation processes, the focus should also be on data utilization, as opposed to focusing on data collection as an end in itself.

PPGIS methodology does not only support human-scale transport planning as a tool for public participation. Place-based methodology is also valuable in deeper research on everyday practices of people, such as regarding emerging mobility services (Weckström et al., 2018), everyday mobility patterns (Ramezani et al., 2021), active living and the related health impacts (Laatikainen et al., 2018), and in the identification of various urban mobility lifestyles (Kajosaari et al., 2019). Here the notion of expanded urban planning (Wallin, 2019) comes onto the scene. To realize truly human scale planning it is not enough to invest in public participation, since the self-organized actions of inhabitants and their everyday life practices also play a crucial role. Ultimately, we will have to ask a question about knowledge integration in dynamic planning processes, if planning processes are to aim at including more, rather than less, participants (Eräranta and Mladenović, 2020).

\section{ACKNOWLEDGEMENT}

This research has received partial support from the Finest Twins project (H2020 grant 856602). 


\section{REFERENCES}

Bailey, K., Grossardt, T., and Ripy, J. (2015). High-performance public involvement. Transportation Research Record: Journal of the Transportation Research Board, 2499, 45-53.

Banister, D. (2008). The sustainable mobility paradigm. Transport Policy, 15, 73-80.

Barnes, G., and Langworthy, P. (2004). Understanding and managing conflict in transportation project public involvement. Transportation Research Record: Journal of the Transportation Research Board, 1895, 102-107.

Bertolini, L., le Clercq, F., and Straatemeier, T. (2008). Urban transportation planning in transition. Transport Policy, 15(2), 69-72.

Bickerstaff, K., Tolley, R., and Walker, G. (2002). Transport planning and participation: the rhetoric and realities of public involvement. Journal of Transport Geography, 10(1), 61-73.

Booth, C., and Richardson, T. (2001). Placing the public in integrated transport planning. Transport Policy, 8(2), 141-149.

Brown, G. (2012). Public Participation GIS (PPGIS) for regional and environmental planning: reflections on a decade of empirical research. Journal of Urban and Regional Information Systems Association, 25(2), 7-18.

Brown, G. (2015). Engaging the wisdom of crowds and public judgment for land use planning using public participation geographic information systems. Australian Planner, 52(3), 199-209.

Brown, G., and Kyttä, M. (2014). Key issues and research priorities for public participation GIS (PPGIS): a synthesis based on empirical research. Applied Geography, 46, 122-136.

Brown, G., and Raymond, C.M. (2014). Methods for identifying land use conflict potential using participatory mapping. Landscape and Urban Planning, 122, 196-208.

Brown, G., Reed, P., and Raymond, C.M. (2020). Mapping place values: 10 lessons from two decades of public participation GIS empirical research. Applied Geography, 16, 102156.

Casello, J.M., Towns, W., Bélanger, J., and Kassiedass, S. (2015). Public engagement in public transportation projects. Transportation Research Record: Journal of the Transportation Research Board, 2537, 88-95.

Cheu, R., Valdez, M., Kamatham, S., and Aldouri, R. (2011). Public preferences on the use of visualization in the public involvement process in transportation planning. Transportation Research Record: Journal of the Transportation Research Board, $2245,17-26$.

Comeau, P., and Rodriguez, D. (2000). Picking publics properly: an artful science. Transportation Research Record: Journal of the Transportation Research Board, 1706, 92- 99.

Eräranta, S., and Mladenović, M.N. (2020). Networked dynamics of knowledge integration in strategic spatial planning processes: a social network approach. Regional Studies, 55(5), 870-882.

Evans-Cowley, J., and Griffin, G. (2012). Microparticipation with social media for community engagement in transportation planning. Transportation Research Record: Journal of the Transportation Research Board, 2307, 90-98. 
Ganapati, S. (2010). Public Participation Geographic Information Systems: a literature survey. In: C.G. Reddick (ed.), Comparative E-Government (pp. 449-466). New York: Springer Science \& Business Media.

Glavić, D., Mladenović, M.N., and Milenković, M. (2019). Decision support framework for cycling investment prioritization. Journal of Advanced Transportation 2019, Article ID 7871426.

Healey, P. (1992). Planning through debate: the communicative turn in planning theory. The Town Planning Review. Liverpool: Liverpool University Press.

Hensher, D.A. (1979). Urban transport planning - the changing emphasis. Socio-Economic Planning Sciences, 13(2), 95-104.

Ibeas, A., dell'Olio, L., and Montequín, R.B. (2011). Citizen involvement in promoting sustainable mobility. Journal of Transport Geography, 19(4), 475-487.

Innes, J.E. (2004). Consensus building: clarifications for the critics. Planning Theory, $3(1), 5-20$.

Kahila-Tani, M. (2015). Reshaping the planning process using local experiences: utilising PPGIS in participatory urban planning. Dissertation, Aalto University.

Kahila-Tani, M., Broberg, A., Kyttä, M., and Tyger, T. (2016). Let the citizens map public participation GIS as a planning support system in the Helsinki Master Plan process. Planning Practice and Research, 31(2), 195-214.

Kahila-Tani, M., Kyttä, M., and Geertman, S. (2019). Does mapping improve public participation? Exploring the pros and cons of using public participation GIS in urban planning practices. Landscape and Urban Planning, 186, 45-55.

Kajosaari, A., Hasanzadeh, K., and Kyttä, M. (2019). Residential dissonance and walking for transport. Journal of Transport Geography, 74, 134-144.

Kennedy, C., Miller, E., Shalaby, A., Maclean, H., and Coleman, J. (2005). The four pillars of sustainable urban transportation. Transport Reviews, 25(4), 393-414.

Laatikainen, T.E., Hasanzadeh, K., and Kyttä, M. (2018). Capturing exposure in environmental health research: challenges and opportunities of different activity space models. International Journal of Health Geographics, 17(1), Article number 29.

Lee, R.J., Sener, I.N., and Jones, S.N. (2017). Understanding the role of equity in active transportation planning in the United States. Transport Reviews, 37(2), 211-226.

Lowry, M.B. (2010). Online public deliberation for a regional transportation improvement decision. Transportation, 37(1), 39-58.

Luna-Reyes, L., Chun, S.A., and Cho, J. (2012). E-participation and transparent policy decision making. Information Polity: The International Journal of Government and Democracy in the Information Age, 17(2), 129-145.

May, A.D. (2015). Encouraging good practice in the development of sustainable urban mobility plans. Case Studies on Transport Policy, 3(1), 3-11.

Misra, A., Gooze, A., Watkins, K., Asad, M., and Le Dantec, C. (2014). Crowdsourcing and its application to transportation data collection and management. Transportation Research Record: Journal of the Transportation Research Board, 2414, 1-8.

Prevost, D. (2006). Geography of public participation: using geographic information systems to evaluate public outreach program of transportation planning studies. Transportation Research Record: Journal of the Transportation Research Board, 1981, 84-91.

Ramezani, S., Laatikainen, T., Hasanzadeh, K., and Kyttä, M. (2021). Shopping trip mode choice of older adults: an application of activity space and hybrid choice models in understanding the effects of built environment and personal goals. Transportation, 48, 505-536. https://doi.org/10.1007/s11116-019-10065-z. 
Schlossberg, M., and Brehm, C. (2009). Participatory geographic information systems and active transportation. Transportation Research Record: Journal of the Transportation Research Board, 2105, 83-91.

Staffans, A., Kahila-Tani, M., and Kyttä, M. (2020). Participatory urban planning in the digital era. In: Stan Geertman and John Stillwell (eds), Handbook of Planning Support Science (pp. 307-321). Cheltenham: Springer International Publishing.

Sustar, H., Mladenović, M.N., and Givoni, M. (2020). The landscape of envisioning and speculative design methods for sustainable mobility futures. Sustainability, 12(6), 2447.

Tang, K.X., and Waters, N.M. (2005). The internet, GIS and public participation in transportation planning. Progress in Planning, 64(1), 7-62.

Wallin, S. (2019). Managing Urban Complexity - Participatory Planning, Self-organization and Co-production of Urban Space. Aalto University publication series, Doctoral dissertations, 159/2019.

Ward, D. (2001). Stakeholder involvement in transport planning: participation and power. Impact Assessment and Project Appraisal, 19(2), 119-130.

Weckström, C., Kujala, R., Mladenović, M.N., and Saramäki, J. (2019). Assessment of large-scale transitions in public transport networks using open timetable data: case of Helsinki metro extension. Journal of Transport Geography, 79, 102470.

Weckström, C., Mladenović, M.N., Ullah, W., Nelson, J.D., Givoni, M., and Bussman, S. (2018). User perspectives on emerging mobility services: ex post analysis of Kutsuplus pilot. Research in Transportation Business and Management, 27, 84-97.

Willson, R. (2001). Assessing communicative rationality as a transportation planning paradigm. Transportation, 28(1), 1-31.

Zhong, T., Young, R.K., Lowry, M., and Rutherford, G.S. (2008). A model for public involvement in transportation improvement programming using participatory geographic information systems. Computers, Environment and Urban Systems, 32(2), 123-133. 